\section{University of New Hampshire}

Carsey School of Public Policy
CARSEY RESEARCH

National Issue Brief \#113

Winter 2017

\title{
On Renewable Energy and Climate, Trump Voters Stand Apart
}

\author{
Lawrence C. Hamilton
}

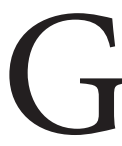

lobally, 2016 was the warmest year on

record, surpassing records set in 2015 and

2014, ${ }^{1}$ and each new record emphasizes the longer-term upward trend. Though not every place on Earth experienced warming effects last year, they were quite evident in many areas. Rising South Pacific sea temperatures caused the largest die-off ever recorded of the coral that composes Australia's Great Barrier Reef, and both Arctic and Antarctic sea ice reached record lows for several months of the year. Among scientists looking at such data, there is overwhelming agreement that human activities are shifting Earth's climate in hazardous directions, and urgent actions are needed to slow this down. ${ }^{2}$ Among U.S. politicians and the public, however, there remain wide divisions on whether humancaused climate change is real, whether scientists agree, and whether anything should be done. ${ }^{3}$

Though climate change received little media attention during the 2016 presidential campaign, recent surveys indicate that climate change and related energy issues are taken seriously by a growing majority of the public.

Though climate change received little media attention during the 2016 presidential campaign, recent surveys indicate that climate change and related energy issues are taken seriously by a growing majority of the public. An example is shown in Figure 1, which charts responses to climate-change and renewable-energy questions from a postelection Polar, Environment, and Science (POLES) survey carried out by Carsey School researchers in November-December 2016. The sample comprised 707 adults from all 50 states. $^{4}$

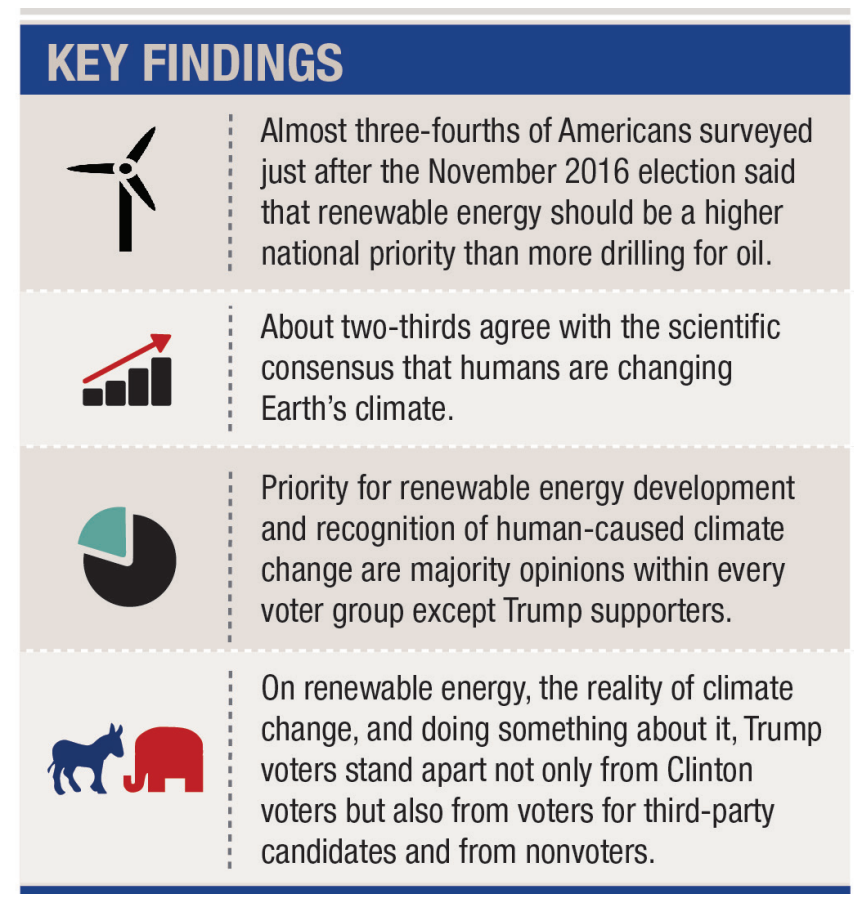

\section{FIGURE 1. VIEWS ON CLIMATE CHANGE AND RENEWABLE ENERGY (POST-ELECTION)}

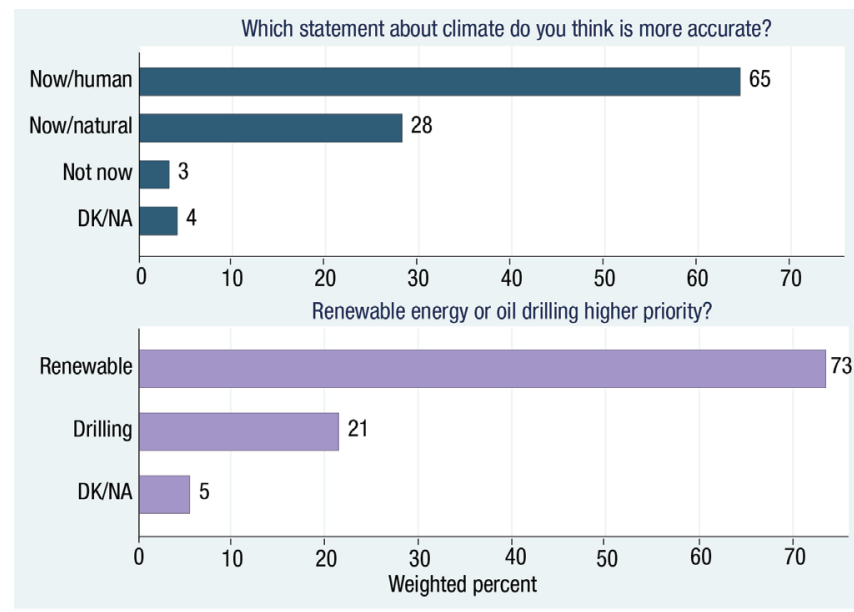

Source: Polar, Environment, and Science (POLES) survey, November-December 2016 
Sixty-five percent of respondents think that climate change is happening now, and it is caused mainly by human activities. Only 28 percent think it is happening but caused mainly by natural forces; 3 percent think climate change is not happening; and 4 percent say they don't know. Seventy-three percent think that increased use of renewable energy should be a higher U.S. priority, compared with just 21 percent who prioritize more exploration and drilling for oil. The percentage who think humans are changing the climate, or renewable energy should be a priority, are both slightly higher on this post-election survey than they were on a survey done just before the election.

Although climate and renewable energy received limited attention during the campaign, candidates Donald Trump and Hillary Clinton both addressed these topics in their platforms. Figure 2 breaks down the climate-change responses of each candidate's supporters along with other voter groups. ${ }^{5}$ Only 25 percent of those who say they voted for Trump agree with the scientific consensus that human activities are changing Earth's climate. In contrast, large majorities not only of Clinton voters but also of third-party voters and nonvoters agree with this view. This nonvoter result is notable because in the U.S. population nonvoters make up a larger group than any candidate's supporters. ${ }^{6}$ The "voted but not for president" group, on the other hand, is small both among all voters and among our survey respondents-only 6 out of 707 , so their high percentages in Figures 2 and 3 must be read with caution. The other groups, however, range from 47 to 241 people, and display similar patterns in the pre-election POLES survey as well (another 704 interviews), lending more confidence to our conclusions about them.

Even on this generally popular topic, less than half of Trump voters think that renewable energy should be a priority. Again, their views stand in contrast with other groups, among whom support for renewable energy ranges from 63 to 100 percent.

Figure 3 shows response to the energy question. Even on this generally popular topic, less than half of Trump voters think that renewable energy should be a priority. Again, their views stand in contrast with other groups, among whom support for renewable

\section{FIGURE 2. PERCENTAGE OF EACH 2016 ELECTION VOTER GROUP SAYING THAT CLIMATE CHANGE IS HAPPENING NOW AND IS HUMAN CAUSED (POST-ELECTION)}

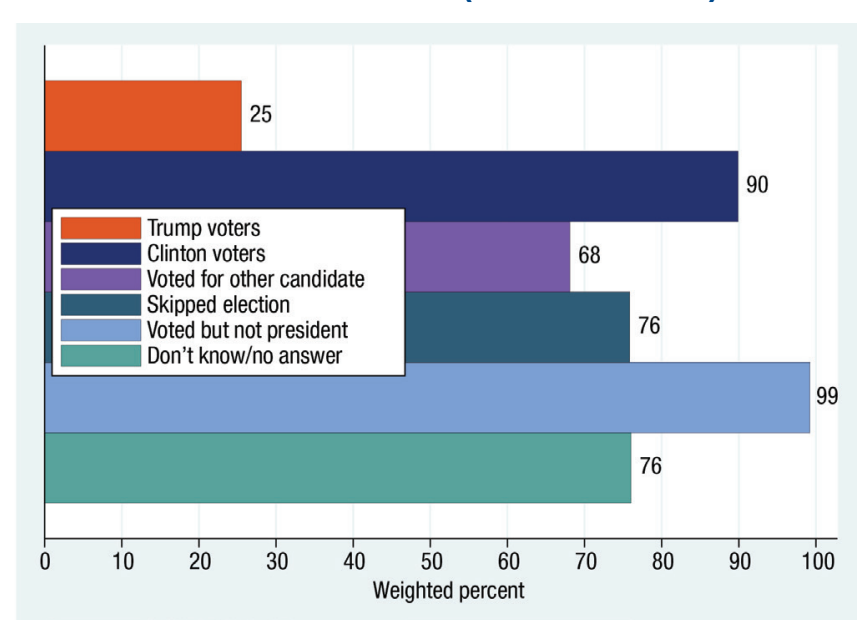

Source: Polar, Environment, and Science (POLES) survey, November-December 2016

\section{FIGURE 3. PERCENTAGE OF EACH 2016 ELECTION VOTER GROUP SAYING THAT RENEWABLE ENERGY SHOULD BE A HIGHER NATIONAL PRIORITY (POST-ELECTION)}

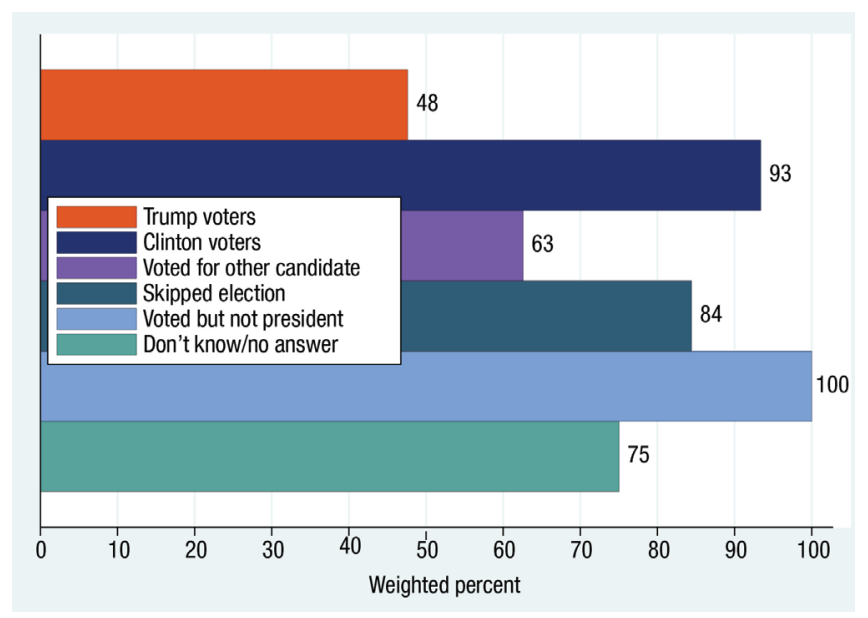

Source: Polar, Environment, and Science (POLES) survey, November-December 2016

energy ranges from 63 to 100 percent. Figure 4 depicts a similar pattern of response to this energy question on the pre-election (August) POLES survey, where a different sample of 704 people were asked who they intended to vote for. On this survey too, Trump supporters stand dramatically apart.

Greater reliance on renewable energy is just one action proposed to reduce the risks of future climate change. Other proposed actions that we asked about in our survey include changes in lifestyles and consumer behavior that would lessen energy use; a 


\section{FIGURE 4. PERCENTAGE OF EACH CANDIDATE'S SUP- PORTERS SAYING THAT RENEWABLE ENERGY SHOULD BE A HIGHER NATIONAL PRIORITY (PRE-ELECTION)}

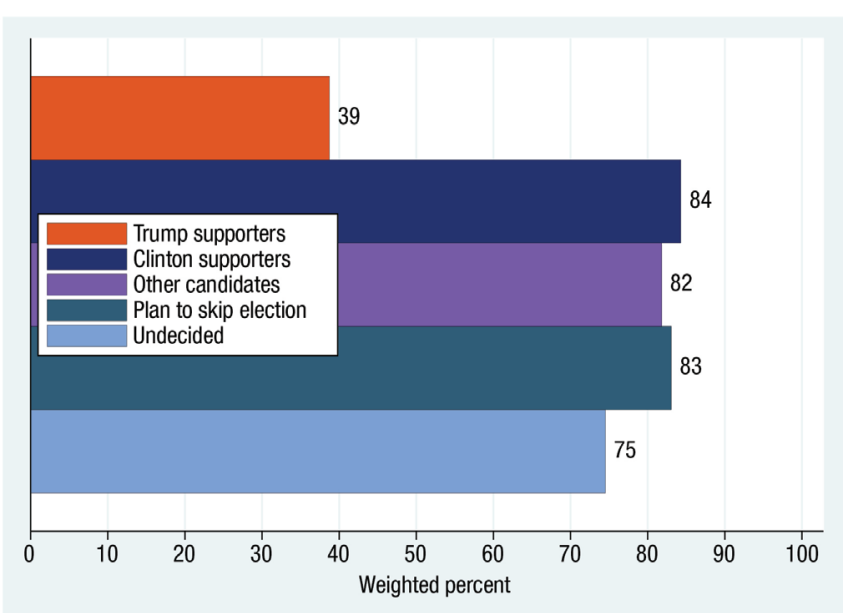

Source: Polar, Environment, and Science (POLES) survey, August 2016

revenue-neutral carbon tax (with revenue returned to consumers); and a "cap-and-trade" system that sets a limit on carbon emissions but allows for trading of rights between emitters. Survey questions asked respondents whether, to reduce the risks of climate change, each of these actions should be a high, medium, or low priority for the United States or not a priority at all. Renewable energy and lifestyle changes prove to be relatively popular, whereas cap-and-trade or a carbon tax do not. Within these variations, however, we see a common theme: Trump voters are much less likely than other voter groups (including third-party voters and nonvoters) to support any action to reduce risks of climate change. This pattern holds whether we look at the November-December post-election survey (Figure 5, 707 respondents), or the August pre-election survey (Figure 6, 704 different respondents).

If human-caused climate change is not happening, or will not have bad effects, then no actions are needed. But very few scientists who study climate believe it is not happening. The overwhelming view among active scientists was succinctly stated by the American Geophysical Union, which has about 55,000 members (10,000 of them atmospheric scientists): "Humaninduced climate change requires urgent action."7 Although public recognition and sense of urgency lag behind science, they are measurably rising. ${ }^{8}$ Given the outcome of the 2016 election, however, and the belief patterns seen in these surveys, the willingness of the United States to respond is in question.

\section{FIGURE 5. PERCENTAGE OF TRUMP AND NON-TRUMP VOTERS GIVING A HIGH PRIORITY TO SPECIFIC ACTIONS TO ADDRESS CLIMATE CHANGE (POST-ELECTION)}

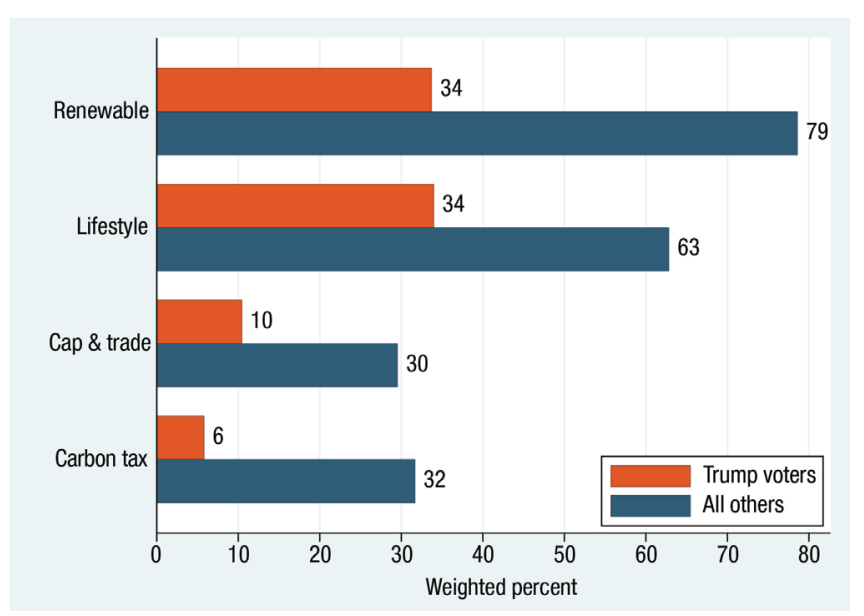

Source: Polar, Environment, and Science (POLES) survey, November-December 2016

\section{FIGURE 6. PERCENTAGE OF TRUMP SUPPORTERS AND ALL OTHERS GIVING A HIGH PRIORITY TO SPECIFIC ACTIONS TO ADDRESS CLIMATE CHANGE (PRE-ELECTION)}

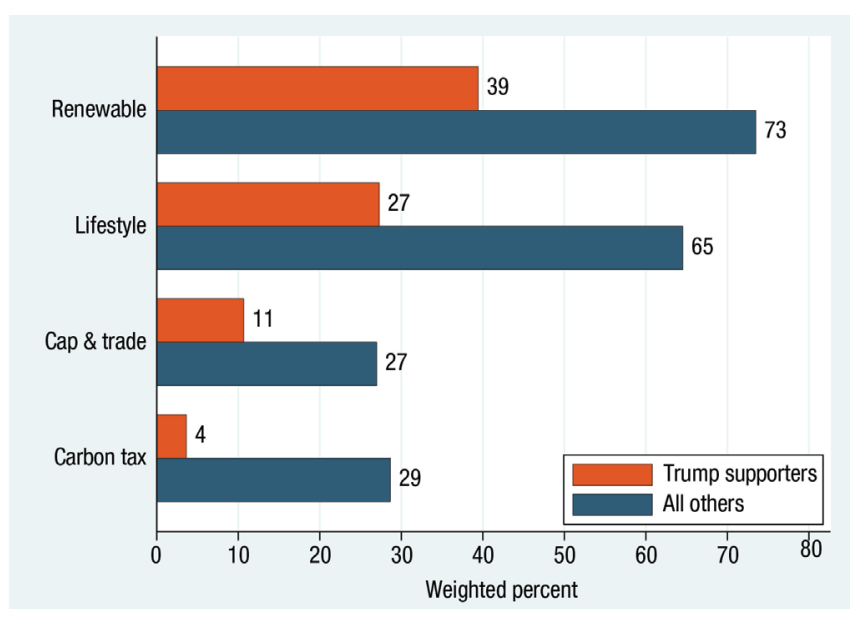

Source: Polar, Environment, and Science (POLES) survey, August 2016 


\section{End n o t e s}

1. NASA, "NASA, NOAA Data Show 2016 Warmest Year on Record Globally" (2017), https://www.nasa.gov/pressrelease/nasa-noaa-data-show-2016-warmest-year-onrecord-globally.

2. J. Cook et al., "Consensus on Consensus: A Synthesis of Consensus Estimates on Human-Caused Global Warming," Environmental Research Letters 11, no. 4 (2016), doi:10.1088/1748-9326/11/4/048002.

3. L.C. Hamilton, "Public Awareness of the Scientific Consensus on Climate," Sage Open (2016a), doi: $10.1177 / 2158244016676296$.

4. Question wording and other details can be found in a report on the pre-election POLES survey, L.C. Hamilton, "Where Is the North Pole? An Election-Year Survey on Global Change" (Durham, NH: Carsey School of Public Policy, University of New Hampshire, 2016b), http:// scholars.unh.edu/carsey/285/.

5. Thirty-one percent of our respondents said they voted for Trump, and 36 percent for Clinton. The remainder reported voting for other candidates (11 percent), not voting (15 percent), voting but leaving their presidential choice blank (1 percent), or declined to answer the question (7 percent). In the election itself, Clinton won the popular vote with 48 percent ( 66 million); Trump received 46 percent (63 million). Other candidates combined received 6 percent (8 million).

6. Roughly 90 million people who were eligible to vote did not do so.

7. American Geophysical Union, "American Geophysical Union Releases Revised Position Statement on Climate Change" (2013), http://news.agu.org/press-release/americangeophysical-union-releases-revised-position-statement-onclimate-change/.

8. Hamilton (2016a).

\section{About the Author}

Lawrence C. Hamilton is professor of sociology and a senior fellow at the Carsey School of Public Policy at the University of New Hampshire (https://carsey.unh. edu/person/lawrence-hamilton).

\section{A c k n o w l ed g ments}

Support for the POLES surveys was provided by the PoLAR Partnership grant from the National Science Foundation (DUE-1239783), with additional help from the New Hampshire EPSCoR Safe Beaches and Shellfish project (IIA-1330641). Any opinions, findings, and conclusions or recommendations expressed in this material are those of the author and do not necessarily reflect the views of the National Science Foundation. The author thanks Michael Ettlinger, Michele Dillon, Curt Grimm, Amy Sterndale, Laurel Lloyd, and Bianca Nicolosi at the Carsey School of Public Policy and Patrick Watson for editorial contributions.

\title{
TI University of New Hampshire Carsey School of Public Policy
}

The Carsey School of Public Policy at the University of New Hampshire is nationally recognized for its research, policy education, and engagement. The school takes on the pressing issues of the twenty-first century, striving for innovative, responsive, and equitable solutions.

\author{
Huddleston Hall • 73 Main Street • Durham, NH 03824 \\ (603) 862-2821 \\ TTY UsERS: DIAL 7-1-1 OR 1-800-735-2964 (RELAY N.H.)
}

carsey.unh.edu 